\title{
Birth weight: a cause for concern over both the short and long terms
}

\author{
Ligia Maria Suppo de Souza Rugolo*
}

Low birth weight has always been a cause for concern among healthcare professionals because it is associated with greater neonatal and infant morbidity and mortality. The set of infants born weighing less than $2,500 \mathrm{~g}$ is heterogenous, since the condition is the result of two adverse conditions - prematurity and/or intrauterine growth restriction - which can act in isolation or in synergy and to varying degrees. In developed countries low birth weight children are predominantly premature, while in developing countries they are small for gestational age infants born to term, i.e. they have suffered an intrauterine growth restriction. Therefore, classified as low birth weight we find newborn infants who have had their intrauterine growth interrupted, but with two distinct diagnoses, for which risk factors and both short and long term prognoses vary. ${ }^{1}$

Two questions motivated follow-up clinics for high-risk infants in the seventies: 1) how do such children grow and develop? 2) what is their morbidity and mortality? In recent decades, as a result of significant increases in the survival rates of ever smaller preterms, the focus of concern in terms of prognosis over both the long and short term has returned to very low weight preterms and in particular those less than $1,000 \mathrm{~g}^{2}$ Nevertheless, interest in and concern about the prognosis of low weight newborn infants, especially small for gestational age full term infants, has also been growing over recent years, due to strong evidence that nutritional conditions at the start of life, including the intrauterine phase, have repercussions for adult health. ${ }^{3}$

The issue of the growth pattern of low weight newborn infants over the first years of life has been heavily discussed, with controversy, in the literature; study results are variable and can't always be compared, since they involve different samples: full term newborn infants with intrauterine growth

\footnotetext{
* PhD. Assistant professor, Department of Pediatrics, Faculdade de Medicina de Botucatu, Universidade Estadual Paulista (UNESP). Chief of the Neonatal Unit, Hospital das Clínicas, Faculdade de Medicina de Botucatu, UNESP, Botucatu, SP, Brazil.
}

Suggested citation: Rugolo LM. Birth weight: a cause for concern over both the short and long terms. J Pediatr (Rio J). 2005;81:359-60. restriction, and/or preterms with appropriate weights and/ or small for gestational age infants. This is an aspect which much be considered when interpreting these studies.

Children born at low weights present an increased risk of progressing with growth deficiency. On the other hand, infants that exhibit catch-up growth, especially rapid increases in weight during the first 2 years of life have shortterm benefits with lower rates of hospitalization and mortality, ${ }^{4}$ although they have an increased risk of progressing to obesity and chronic diseases in adulthood, including hypertension, coronary disease and diabetes. ${ }^{2,3}$

The first year of life is a period of greater vulnerability to multiple nutritional, infectious and environmental afflictions and monitoring infant growth, particularly during this period, is a basic healthcare action which assumes great importance, particularly in developing countries, where around $1 / 3$ of children exhibit inadequate growth. In Brazil the figure is around $10 \%$ for children under 5 years old; and low birth weight, basically caused by intrauterine growth restriction, affects around $10 \%$ of live births. ${ }^{5,6}$

Despite this alarming situation and the many different questions that have not yet been answered about the growth prognosis of low weight newborn infant, the subject has been little studied in our country. For this reason, the study undertaken by Motta et al. ${ }^{7}$ and presented in this edition of the Jornal de Pediatria merits special attention since it is a valuable contribution on the theme. The title of the article is a question that is of great interest to all pediatricians: "Does birth weight affect nutritional status at the end of first year of life?"

The question is answered with great care in this welldesigned study with a large sample and criteria-based methodology, in which the authors investigated the association between low birth weight and nutritional status at the end of the first year of life. In addition to birth weight, a number of other factors known to influence the nutritional condition of children were also investigated. These include: socioeconomic and environmental factors, duration of maternal breastfeeding and episodes of diarrhea.

The results reveal an elevated frequency (22.2\%) of children in situations of nutritional risk (weight/age below 
the 10th percentile of the NCHS curve) at one year of age, with the risk of this taking place increasing significantly in inverse proportion to birth weight, culminating with an increase of 29 times the risk for children born weighing less than $2,500 \mathrm{~g}^{7}$

Episodes of diarrhea were very frequent, but attention is drawn to the fact that they were not associated with nutritional risk at the end of the first year of life, which the authors discuss carefully in order not to minimize concern with the classic interaction between infection and malnutrition. It should be noted that this study did not evaluate the exact number of episodes or the severity of the disease. Reviewing the literature, one finds that while diarrhea and early weaning are frequently referred to as risk factors for malnutrition, it is studies of hospitalized children that document significant participation by them. ${ }^{8}$

One important aspect identified by this study was that insufficient birth weight $(2,500-2,999 \mathrm{~g})$ increased the chance of insufficient weight at one year by seven times. This is a group of infants who have not received much attention, either in daily practice or in research. ${ }^{6}$ However, in developing countries, around $35 \%$ of infants born to term at weights from 2,500 to 3,200 g exhibit intrauterine growth restriction, which is a warning to be concerned about the growth prognosis of these children. ${ }^{9}$

Studies in developed countries of the growth of small for gestational age children have shown that the majority of them exhibit catch-up growth and as the first years of life progress are able to achieve a growth channel that is within the limits of normality on the reference curves, but that at the end of the first year of life, around $30-40 \%$ of them have not yet managed to pass the lower limit for normal weight. 10 In the study carried out by Motta et al. ${ }^{7}$ children were weighed at two points (birth and 1 year of age), so growth curves cannot be assessed.

The question can be posed as to whether these children are in a phase of recuperation or if perhaps their nutritional status will deteriorate over the following years since, as Motta \& Silva reported in a previous study of the nutritional evaluation of children under 11 years in a low-income community, the nutritional status of toddlers and schoolchildren was worse than that of the infants. ${ }^{11}$
The research by Motta et al., 7 by demonstrating incontrovertibly the importance of birth weight to nutritional prognosis at the end of the first year of life, motivates us to discover the risk factors to which our patients are exposed since they undoubtedly vary across the different regions of our country and also encourages us to perform follow-up of low birth weight infants.

One important message that this study sends is that biological determinants of nutritional risk are more important that environmental ones in a population living in unfavorable socioeconomic conditions, which is of use to guide preventative healthcare activities. The challenge has been laid down for future studies to investigate strategies that could reduce the rates of low birth weight.

\section{References}

1. Wilcox AJ. On the importance - and the unimportance - of birthweight. Int J Epidemiol. 2001; 30: 1233-41.

2. Rugolo LM. Crescimento e desenvolvimento a longo prazo do prematuro extremo. J Pediatr (Rio J). 2005;81 (1 Supl):S101-10.

3. Lucas A, Fewtrell MS, Cole TJ. Fetal origins of adult disease - the hypothesis revisited. Br Med J. 1999;319:245-9.

4. Victora CG, Barros FC, Horta BL, Martorell R. Short-term benefits of catch-up growth for small-for-gestational-age infants. Int J Epidemiol. 2001;30:1325-30.

5. Ministério da Saúde. Política nacional de alimentação e nutrição. Brasília: Secretaria de Políticas de Saúde, Instituto Nacional de Alimentação e Nutrição; 2000.

6. Nóbrega FJ. Antropometria, patologias e malformações congênitas do recém-nascido brasileiro e estudos de associação com algumas variáveis maternas. J Pediatr (Rio J). 1985;59 (1 Supl):S6-144.

7. Motta ME, Silva GA, Araújo OC, Lira PI, Lima MC. O peso ao nascer influencia o estado nutricional ao final do primeiro ano de vida? J Pediatr (Rio J). 2005;81:377-82.

8. Lima MC, Motta ME, Santos EC, Silva GA. Determinants of impaired growth among hospitalized children - a case-control study. São Paulo Med J. 2004;122:117-23.

9. Balcazar H, Keefer L, Chard T. Use of anthropometric indicators and maternal risk factors to evaluate intrauterine growth retardation in infants weighing more than 2500 grams at birth. Early Hum Dev. 1994;36:147-55.

10. Wikland-Albertsson $\mathrm{K}$, Wennergren $\mathrm{G}$, Wennergren $\mathrm{M}$, Vilbergsson G, Rosberg S. Longitudinal follow-up of growth in children born small for gestational age. Acta Paediatr. 1993;82:438-43.

11. Motta ME, Silva GA. Desnutrição e obesidade em crianças: perfil de uma comunidade de baixa renda. J Pediatr (Rio J). $2001 ; 77: 288-93$. 